\title{
Durability of self-cleaning cement-based materials
}

\author{
M.V. Diamanti ${ }^{1}$, N. Luongo ${ }^{2}$, S. Massari ${ }^{2}$, S. Lupica Spagnolo ${ }^{2}$, B. Daniotti ${ }^{2}$, MP. Pedeferri ${ }^{1}$ \\ 1 Politecnico di Milano, Department of Chemistry, Materials and Chemical Engineering "G. Natta", Via \\ Mancinelli 7, 20131 Milan, Italy
}

2 Politecnico di Milano, Department of Architecture, Built environment and Construction engineering, Via Ponzio 31, 20133 - Milan, Italy

\begin{abstract}
The use of self-cleaning materials as building materials is gaining more and more interest, but their performance characterization over time has been poorly investigated. For this purpose, accelerated durability tests were carried out on different self-cleaning materials, either based on photocatalytic principles (i.e. containing $\mathrm{TiO}_{2}$ ) or on the lotus effect, which were subjected to UV radiation, rain, freezethaw and thermal cycles variations. The accelerated ageing tests program involved different commercial materials and was aimed at a second step of characterization of their photocatalytic activity and selfcleaning ability, in order to investigate their durability and the retention of such functionality over time. With this aim, rhodamine $B(R h-B)$ dye degradation tests were performed. The experimental campaign proved the actual self-cleaning behaviour of these materials in their freshly produced state, but it also demonstrated the detrimental effect of ageing on their performances. Moreover, issues related to the test method emerged with special reference to the evaluation of materials durability.
\end{abstract}

\section{Introduction}

The development of photoactive materials with self-cleaning and depolluting properties is a hot topic in materials science thanks to their impact on several technologies, in a wide range of contexts of applications, with special reference in this work to building materials [1-4]. Anatase phase titanium dioxide $\left(\mathrm{TiO}_{2}\right)$ is the largest used photocatalyst, with increasing applications ranging from air quality control to renewable energies, to green building materials for zero energy communities. UV irradiation is the condicio sine qua non photocatalyst can be activated.

Photoactive materials are particularly suitable for application in urban construction, by exploiting their potential in building envelops. Titanium dioxide can accelerate degradation reactions, generating positive repercussions on the well-known environmental issue: the material contributes significantly to the decomposition of pollutants which, by means of its superhydrophilicity, are then washed away by rain; hence, the de-polluting effect is coupled with self-cleaning that is equally important in the built environment [5-10].

Adding $\mathrm{TiO}_{2}$, either as coating or in bulk, is not the only way to produce self-cleaning building materials: indeed, the lotus effect has also been widely investigated as a means to decrease the adhesion of contaminants on the surface of materials. This method takes advantage of specific surface conformation and chemistry, which modify interactions between the surface and the outer environment, but it confers to the material no depolluting capability, as no reactive chemical species is produced on such surfaces [1113].

Several studies have been presented in the literature concerning the evaluation of photocatalytic and selfcleaning properties of these materials, both at a laboratory level and in real scale applications. However, their performance characterization in time, with particular reference to the evolution of the materials 
behaviour with ageing, has been poorly investigated so far, and some of the works put a question mark on the durability of the photocatalytic and self-cleaning effect [14-21].

Within the construction sector, durability joins the fields of physics, chemistry and materials nanotechnology. These contexts, even if dialectically far, converge simultaneously into the building management framework: knowing the attitude of materials over time, and therefore of building components, is the best way to predict their behaviour and thus the dynamics of their performance in a life cycle perspective. In this sense, durability completes the concept of maintenance, which cannot be properly planned without the essential durability knowledge and whose costs cannot be effectively controlled, within a Life Cycle approach. By forecasting performance decays of materials, there is a chance to act in a preventative manner.

With these premises, the work here presented is aimed at evaluating the durability of self-cleaning commercial materials, together with their photocatalytic properties when present. As a consequence, accelerated ageing tests in a climatic chamber were set up to investigate the performance decay and physical degradation over time, in order to establish the system of durability knowledge essential to evaluate the evolution of self-cleaning effect and degradation of pollutants during these materials service life. To meet this aim, self-cleaning tests were repeated at time intervals to observe the modification of performances with the progression of ageing cycles.

\section{Experimental}

\subsection{Materials}

The experimental campaign was set for 144 samples which differ for composition and finishing. For the sake of simplicity, only some of them will be described: in Table 1 the list of samples here considered is presented, labelled according to their composition and finishing. Seven different series of commercial cement-based materials are considered. Samples differ in terms of surface finishing (smooth, sandblasted) and composition (no addition, $\mathrm{TiO}_{2}$ in bulk, lotus effect). Samples of six series out of seven, starting with label PIZ, were provided by PIZ Srl; one last material was also tested, and used as reference photocatalytic material.

Table 1 - Commercial samples labels and corresponding characteristics

\begin{tabular}{ll} 
Sample label & Description \\
\hline REF-T & Reference photocatalytic mortar, smooth \\
PIZ-STD-L & Standard mortar, smooth \\
PIZ-STD-S & Standard mortar, sandblasted \\
PIZ-T-L & Photocatalytic mortar, smooth \\
PIZ-T-S & Photocatalytic mortar, sandblasted \\
PIZ-LT-L & Mortar with lotus effect, smooth \\
PIZ-T-LT-L & Photocatalytic mortar with lotus effect, smooth
\end{tabular}

\subsection{Accelerated ageing}

Samples were subjected to accelerated ageing cycles in a climate chamber, defined as reported in Table 2. Each ageing cycle consisted of two sub-cycles, A and B, characterized by different atmospheric conditions in terms of humidity, temperature, and exposure to UV radiation. 
Table 2 - Conditions of one single accelerated ageing cycle

\begin{tabular}{lccccc} 
& Phase & $\mathbf{T}_{\text {air }}\left[{ }^{\circ} \mathbf{C}\right]$ & $\mathbf{T}_{\text {rain }}\left[{ }^{\circ} \mathbf{C}\right.$ ] & UR [\%] & Duration [min] \\
\hline \multirow{4}{*}{ Sub-cycle A } & Rain & 20 & $15-20$ & - & 60 \\
& Freeze & -20 & - & - & 90 \\
& Wet heat & 55 & - & 95 & 60 \\
& Dry heat, no UV & 70 & - & 40 & 80 \\
\hline Sub-cycle B & UV irradiation & 30 & - & 40 & 80
\end{tabular}

The assessment of degradation level was carried out after $50\left(T_{1}\right), 100\left(T_{2}\right)$ and $150\left(T_{3}\right)$ cycles of ageing. With this aim, visual observations (qualitative analyses), colour measurements and photocatalysis tests were performed, and compared with results of same tests performed on non-aged samples.

The results of quantitative analyses (i.e. colour measurements and photocatalysis tests) are here reported. The former were performed with the use of a reflectance spectrophotometer Konica Minolta CM-2600d; and colour coordinates $L^{*}, a^{*}, b^{*}$ according to CIELab reference system were adopted. Colour variations at time of analysis, $t$, with respect to the initial surface colour measured before ageing at time zero, were quantified in terms of variation of each single colour coordinate: $\Delta \mathrm{L}^{*}, \Delta \mathrm{a}^{*}$ and $\Delta \mathrm{b}^{*}$.

All tests were done on three samples of the same material tested in same conditions to evaluate repeatability. In all cases, very good adherence of results among samples with the same composition was observed, hence all results here presented are given as average values of the three tests.

\subsection{Photocatalysis tests}

Moreover, photocatalysis tests were performed according to the Italian standard UNI 11259. Rhodamine B (Rh-B), a pink organic dye, was used as a model substance and its degradation was taken as indication of photocatalytic and self-cleaning ability. $2 \mathrm{ml}$ of an aqueous Rh-B solution $\left(10^{-5} \mathrm{M}\right)$ were applied on samples and let dry for $24 \mathrm{~h}$, then surface colour was monitored periodically to observe colour changes over time, which are a consequence of dye degradation. According to the mentioned standard, a material is considered photocatalytic if the variation in colour intensity, measured exclusively on the colour coordinate $\mathrm{a}^{*}$, exceeds $20 \%$ after $4 \mathrm{~h}$ irradiation and $50 \%$ after $24 \mathrm{~h}$ irradiation.

\section{Results and discussion}

\subsection{Accelerated ageing}

Accelerated ageing had a dramatic effect on the durability of all samples considered, both photocatalytic and non-photocatalytic. Indeed, it must be considered that the ageing cycles applied to the materials were rather challenging, involving UV irradiation, rain and freezing. Therefore the physical damage occurring to samples was evident even visually from the second series of cycles, see as example sample REF-T in Figure 1. Yet, no relevant mass loss was observed (data not reported).

From a quantitative point of view, ageing caused a darkening of the samples surfaces, with corresponding decrease in the colour coordinate associated to lightness, L* (Figure 2). The a* coordinate, representing $\mathrm{red} / \mathrm{green}$ hues, was almost unchanged, with variations well below the limit of detectability by human eye (Figure 3), while the $b^{*}$ coordinate, responsible for the blue/yellow hues, experienced in all cases an increase towards positive values (yellow range), indicating a yellowing of the surface (Figure 4). This is typically connected to surface soiling, degradation of organic admixtures present in the mortar mix, as well as to possible activation of degradation mechanisms within the photocatalytic materials - which is not considered in this case, given the absence of relevant pollutant sources within the climate chamber. 

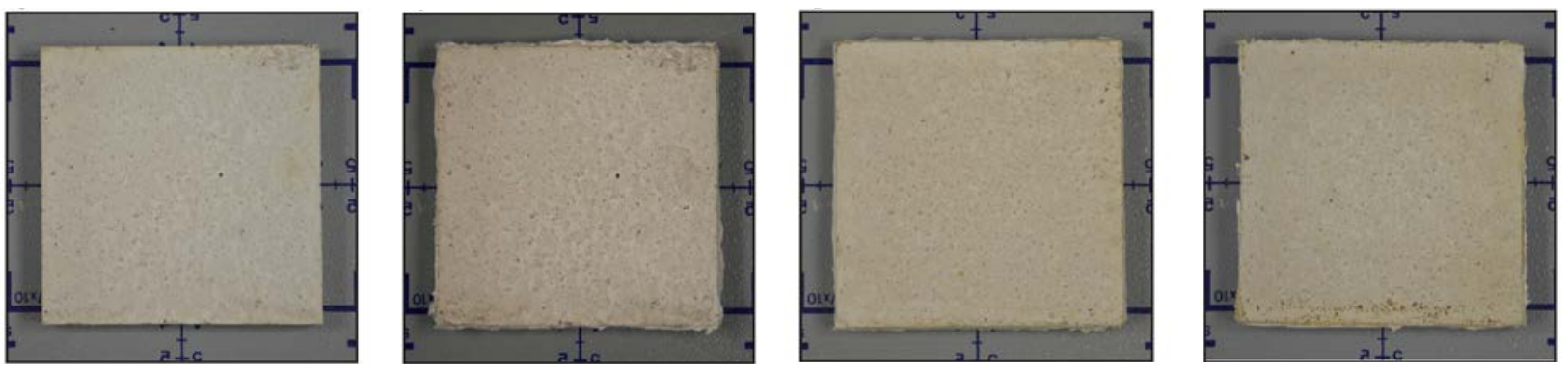

Figure 1 - From left to right: sample REF-T aspect before ageing $(t=0)$, after 50 cycles $\left(t=T_{1}\right)$, after 100 cycles $\left(t=T_{2}\right)$ and after 150 cycles $\left(t=T_{3}\right)$

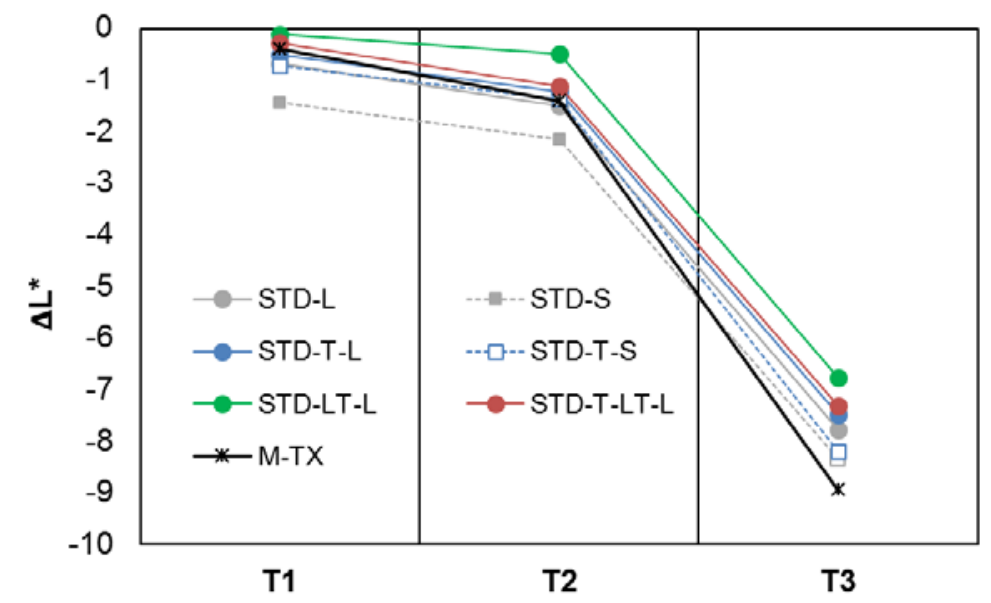

Figure 2 - Lightness change, $\Delta \mathrm{L}^{*}$, due to accelerated ageing

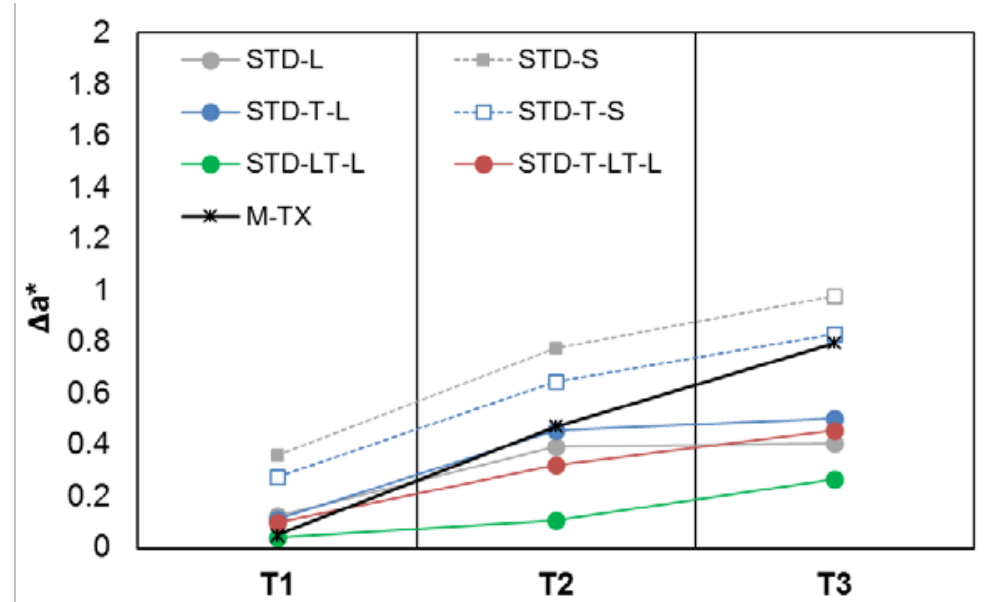

Figure 3 - Red/green hue change, $\Delta \mathrm{a}^{*}$, due to accelerated ageing 


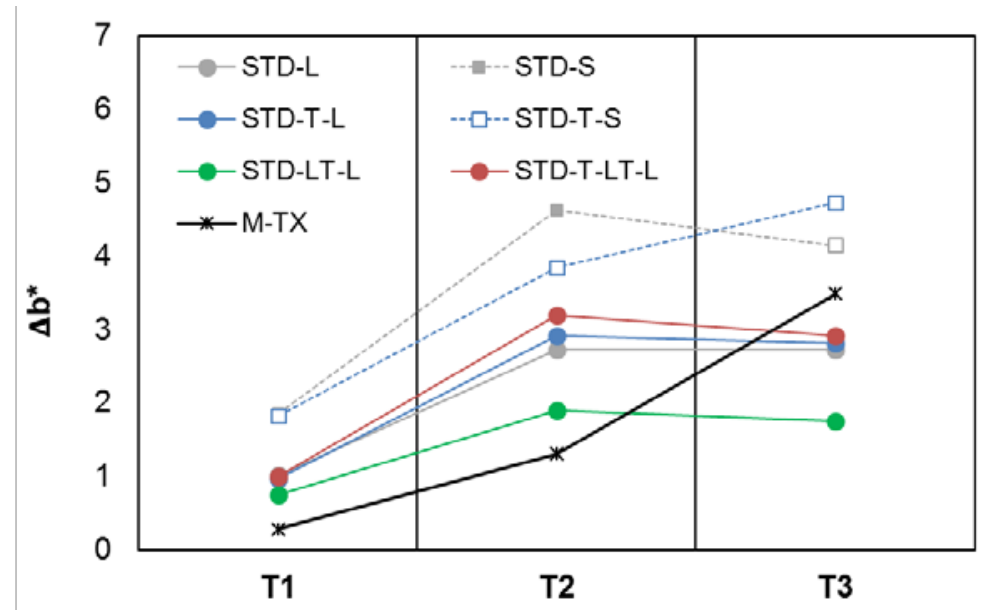

Figure $4-$ Yellow/blue change, $\Delta \mathrm{b}^{*}$, due to accelerated ageing

Concerning a brief comparison among the performances of the different materials tested, the only relevant differences observed were:

- a faster loss of performance - i.e., faster colour variation - on the reference samples REF-T as compared with fiber-reinforced mortars

- an overall better behaviour of the samples with lotus effect, where lightness was better maintained in time and yellowing was less accentuated, out of the range of detectability by human eye.

As mentioned, these cycles were particularly onerous to the materials investigated, but this was the desired effect: in fact, the extent of colour variation was monitored but was not taken in large consideration, due to the difficulty in associating colour variations caused by accelerated ageing to actual colour changes that the material could undergo in real exposure conditions. This is particularly true if the contribution of atmospheric soiling is considered, which is the most relevant effect leading to colour changes on the surface of building envelope materials. The effect of natural ageing and related colour variations have already been discussed in a previous work [15]. In this case, the intent was that of causing a relatively large damage to the materials investigated, in order to assess the possible maintaining of photocatalytic and selfcleaning properties in time.

\subsection{Photocatalysis tests}

Given these premises, results related to photocatalytic and self-cleaning activity, evaluated following the Italian standard UNI 11259, are reported in Figure 5. In particular, in the histograms it is highlighted whether samples reach the threshold indicated by the same standard in order to be defined photocatalytic after $4 \mathrm{~h}$ (left) or $24 \mathrm{~h}$ (right) of test. For each sample, four bars are reported: these represent the four different times of test, i.e., on new samples, after 50 cycles, after 100 cycles and after 150 cycles of ageing, from top to bottom, as indicated in the inset.

Considering first of all non-aged conditions, it is possible to notice that all declared photocatalytic samples exceed both thresholds of acceptability. Interestingly, at $t=\mathrm{T}_{0}$ also the standard fiber-reinforced sample without presence of photocatalytic admixture (PIZ-STD-L) seems to show a photocatalytic activity after $4 \mathrm{~h}$ test, although the requisite at $24 \mathrm{~h}$ is not met, which confirms the non-photoactivity of the material based on the Italian standard requirements.

On the other hand, the sample characterized by lotus leaf effect (PIZ-LT-L) also shows what the Italian standard considers to be a photocatalytic activity: for this reason, from the very beginning we chose to define the tested property as "photocatalytic and self-cleaning activity", since the lotus effect is actually 
capable of conferring to the surface a self-cleaning effect and therefore help the recovery of its initial colour, although it is not possible to consider the pollutant (in this case, the dye) degraded.

Finally, the activity of the photocatalytic sandblasted sample (PIZ-T-S) is lower compared to that of the smooth one: this is due to the mortar composition, which contains glass fibers. Once the mortar is sandblasted to achieve the rough surface, glass fibers appear at the surface, which are not photocatalytic, thus the dye absorbed on the glass spots cannot be degraded. This decreases the overall colour change of the surface, which is measured as an average on a $15 \mathrm{~mm}$ spot, a dimension sufficient to include both mortar and glass fibers.

After ageing, almost all materials experienced a decay in photoactivated properties. in particular, the commercial mortar containing $3 \% \mathrm{TiO}_{2}$ could not be considered photocatalytic anymore on the basis of the standard requirements. After the first 50 cycles of ageing, the PIZ-T-L sample at least after $4 \mathrm{~h}$ irradiation reached and exceeded the minimum degradation level required by the standard, and almost reached it after $24 \mathrm{~h}$ of test; for longer ageing the required photocatalytic activity levels were not reached. Surprisingly, the only material that maintained a suitable change in $\Delta \mathrm{a}^{*}$ - which, as pointed out, corresponds in this case not to photodegradation but rather to self-cleaning properties - is the one characterized by the lotus effect, PIZ-LT-L. This is coherent with the smaller colour variation experienced by these samples, which denotes a limited ageing.

Relatively few articles report on the durability of self-cleaning cementitious systems, although this should be a key point to evaluate, given the long service life that is typical of construction materials [15,20,22-24]. Some researches on the subject pointed out a decrease in photocatalytic and self-cleaning performances over time, although a good recover of photoactivity is allowed by a cleaning of the materials surfaces to eliminate reaction byproducts and atmospheric soiling that tend to deactivate the desired surface reactions $[15,25]$. It is opinion of the authors that results here presented point out a clear decay in the photocatalytic properties of samples containing $\mathrm{TiO}_{2}$ upon ageing in such demanding conditions, but also that such results are not fully conclusive about the long-term behaviour of the materials investigated. This is due to the type of test identified by the Italian standard as representative of photocatalytic activity, which seems to be more suitable to investigate the self-cleaning character of the materials, rather than their ability to degrade pollutants. Indeed, current ISO standards suggest the use of dye discolouration mechanisms to evaluate the self-cleaning ability of photocatalytic materials - and may be extended to other types of self-cleaning mechanisms, as proved by results here presented [26]. On the other hand, the degradation of gaseous pollutants is generally indicated as most suitable to assess the actual photocatalytic efficiency [27], in spite of some shortcomings also presented by these methods, such as the need for specific flow regime, pollutant concentration and other factors that concur to determine the contact time between pollutant and photocatalyst surface, which is a key parameter for efficiency evaluation, although it is very difficult to reproduce $[28,29]$. 

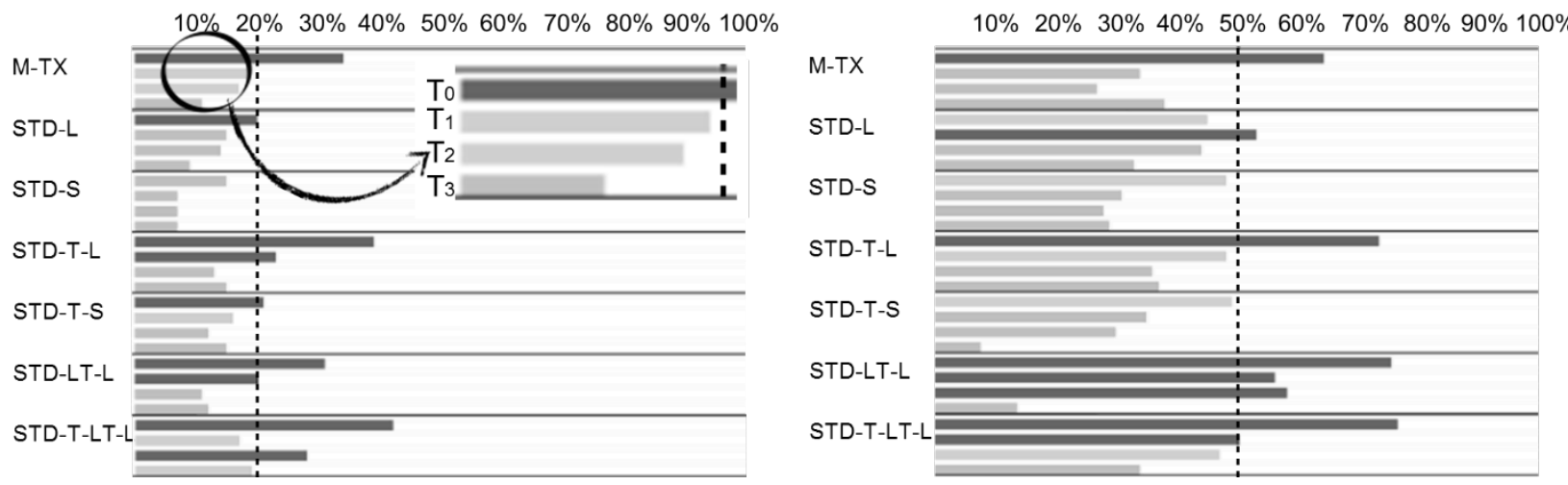

Figure 5 - Results of photocatalysis tests before $\left(T_{0}\right)$ and after ageing $\left(T_{1}, T_{2}, T_{3}\right)$ : percent Rh-B degradation, calculated as percent variation in a* coordinate. Left: after $4 \mathrm{~h}$ of irradiation; right: after $24 \mathrm{~h}$ of irradiation. Thresholds indicated by UNI 11259 are also reported.

\section{Conclusions}

This work was dedicated to the evaluation of photocatalytic and self-cleaning properties of façade mortars either containing $\mathrm{TiO}_{2}$, or modified to achieve a lotus effect (self-cleaning by superhydrophobicity), and the maintaining of these properties after materials ageing. The mortars were subjected to severe ageing cycles which included both rain and freeze-thaw simulation. Photocatalysis tests were performed following the Italian standard method that involves the discoloration of the organic dye rhodamine B. Results indicate a loss of photocatalytic activity with ageing, as expected. Yet, the materials that gave the best performances were those characterized by a lotus effect, which were not expected to give positive results in the photocatalysis tests. Therefore, a conclusion can be drawn also on the test methodology, which should be regarded as an evaluation of self-cleaning properties rather than photocatalytic ones. 


\section{References}

[1] M.V. Diamanti, M. Pedeferri, Concrete, mortar and plaster using titanium dioxide nanoparticles: applications in pollution control, self-cleaning and photo sterilization, in: Nanotechnol. Eco-Effic. Constr., Elsevier, 2013: pp. 299-326.

http://linkinghub.elsevier.com/retrieve/pii/B9780857095442500130 (accessed January 15, 2016).

[2] E. Boonen, A. Beeldens, Photocatalytic roads: from lab tests to real scale applications, Eur. Transp. Res. Rev. 5 (2013) 79-89. doi:10.1007/s12544-012-0085-6.

[3] M. Fleisch, D. Bahnemann, Photocatalitically active concrete: How innovative construction materials can contribute to the degradation of dangerous air pollutants, Beton-Stahlbetonbau. 112 (2017) 4753. doi:10.1002/best.201600506.

[4] M. M. Oymak, D. Uner, Patents on Photocatalyst Incorporated Cement Based Materials, Recent Pat. Catal. 2 (2014) 116-129. doi:10.2174/2211548X113026660007.

[5] O. Carp, C.L. Huisman, A. Reller, Photoinduced reactivity of titanium dioxide, Prog. Solid State Chem. 32 (2004) 33-177. doi:10.1016/j.progsolidstchem.2004.08.001.

[6] A. Fujishima, X. Zhang, D. Tryk, Heterogeneous photocatalysis: From water photolysis to applications in environmental cleanup, Int. J. Hydrog. Energy. 32 (2007) 2664-2672. doi:10.1016/j.ijhydene.2006.09.009.

[7] K. Hashimoto, H. Irie, A. Fujishima, $\mathrm{TiO}_{2}$ photocatalysis: a historical overview and future prospects, Jpn. J. Appl. Phys. 44 (2005) 8269.

[8] P. Munafò, G.B. Goffredo, E. Quagliarini, $\mathrm{TiO}_{2}$-based nanocoatings for preserving architectural stone surfaces: An overview, Constr. Build. Mater. 84 (2015) 201-218. doi:10.1016/j.conbuildmat.2015.02.083.

[9] A. Maury-Ramirez, K. Demeestere, N. De Belie, T. Mäntylä, E. Levänen, Titanium dioxide coated cementitious materials for air purifying purposes: Preparation, characterization and toluene removal potential, Build. Environ. 45 (2010) 832-838. doi:10.1016/j.buildenv.2009.09.003.

[10] R. Wang, K. Hashimoto, A. Fujishima, M. Chikuni, E. Kojima, A. Kitamura, M. Shimohigoshi, T. Watanabe, Photogeneration of highly amphiphilic TiO 2 surfaces, Adv. Mater. 10 (1998) 135-138.

[11] B. Bhushan, M. Nosonovsky, Y.C. Jung, Lotus Effect: Roughness-Induced Superhydrophobic Surfaces, in: B. Bhushan (Ed.), Nanotribology Nanomechanics Introd., Springer Berlin Heidelberg, Berlin, Heidelberg, 2008: pp. 995-1072. doi:10.1007/978-3-540-77608-6_19.

[12] H. Bai, L. Zhang, D. Gu, Micrometer-sized spherulites as building blocks for lotus leaf-like superhydrophobic coatings, Appl. Surf. Sci. 459 (2018) 54-62. doi:10.1016/j.apsusc.2018.07.183.

[13] S.S. Latthe, R.S. Sutar, V.S. Kodag, A.K. Bhosale, A.M. Kumar, K. Kumar Sadasivuni, R. Xing, S. Liu, Selfcleaning superhydrophobic coatings: Potential industrial applications, Prog. Org. Coat. 128 (2019) 5258. doi:10.1016/j.porgcoat.2018.12.008.

[14] E. Boonen, A. Beeldens, I. Dirkx, V. Bams, Durability of Cementitious Photocatalytic Building Materials, Catal. Today. 287 (2017) 196-202. doi:10.1016/j.cattod.2016.10.012.

[15] M.V. Diamanti, R. Paolini, M. Rossini, A.B. Aslan, M. Zinzi, T. Poli, M.P. Pedeferri, Long term selfcleaning and photocatalytic performance of anatase added mortars exposed to the urban environment, Constr. Build. Mater. 96 (2015) 270-278. doi:10.1016/j.conbuildmat.2015.08.028.

[16] A. Calia, M. Lettieri, M. Masieri, Durability assessment of nanostructured TiO2 coatings applied on limestones to enhance building surface with self-cleaning ability, Build. Environ. 110 (2016) 1-10. doi:10.1016/j.buildenv.2016.09.030.

[17] M.-Z. Guo, A. Maury-Ramirez, C.S. Poon, Photocatalytic activities of titanium dioxide incorporated architectural mortars: Effects of weathering and activation light, Build. Environ. 94, Part 1 (2015) 395402. doi:10.1016/j.buildenv.2015.08.027.

[18] P. Munafò, E. Quagliarini, G.B. Goffredo, F. Bondioli, A. Licciulli, Durability of nano-engineered $\mathrm{TiO}_{2}$ self-cleaning treatments on limestone, Constr. Build. Mater. 65 (2014) 218-231. doi:10.1016/j.conbuildmat.2014.04.112.

[19] B. Daniotti, S. Lupica Spagnolo, R. Galliano, The Durability Experimental Evaluation of Photocatalytic Cement-Based Materials. In: 12th International Conference on Durability of Building Materials and Components, Porto (Portugal), 12-15 April 2011, vol. 1, p. 225-232. 
[20] C. Pirola, D.C. Boffito, S. Vitali, C.L. Bianchi, Photocatalytic coatings for building industry: study of 1 year of activity in the NO x degradation, J. Coat. Technol. Res. 9 (2012) 453-458. doi:10.1007/s11998011-9381-7.

[21] M.V. Diamanti, F. Lollini, M.P. Pedeferri, L. Bertolini, Mutual interactions between carbonation and titanium dioxide photoactivity in concrete, Build. Environ. 62 (2013) 174-181. doi:10.1016/j.buildenv.2013.01.023.

[22] L. Graziani, E. Quagliarini, F. Bondioli, M. D'Orazio, Durability of self-cleaning $\mathrm{TiO}_{2}$ coatings on fired clay brick façades: Effects of UV exposure and wet \& dry cycles. Build. Environ. 71 (2014) 193-203. doi:10.1016/j.buildenv.2013.10.005.

[23] A. Maury-Ramirez, K. Demeestere, N. De Belie, Photocatalytic activity of titanium dioxide nanoparticle coatings applied on autoclaved aerated concrete: effect of weathering on coating physical characteristics and gaseous toluene removal. J. Hazard. Mater. 211-212 (2012) 218-225. doi:10.1016/j.jhazmat.2011.12.037.

[24] M.M. Hassan, H. Dylla, L.N. Mohammad, T. Rupnow, Evaluation of the durability of titanium dioxide photocatalyst coating for concrete pavement. Constr. Build. Mater. 24 (2010) 1456-1461. doi:10.1016/j.conbuildmat.2010.01.009.

[25] M. Etxeberria, M-Z. Guo, A. Maury-Ramirez, C.S. Poon, Influence of dust and oil accumulation on effectiveness of photocatalytic concrete surfaces. J. Environ. Eng. (US) 143 (2017) 04017040. doi:10.1061/(ASCE)EE.1943-7870.0001239.

[26] ISO 10678:2010: Fine ceramics (advanced ceramics, advanced technical ceramics) - Determination of photocatalytic activity of surfaces in an aqueous medium by degradation of methylene blue

[27] ISO 22197: Fine ceramics (advanced ceramics, advanced technical ceramics) - Test method for airpurification performance of semiconducting photocatalytic materials

[28] A. Strini, S. Cassese, L. Schiavi, Measurement of benzene, toluene, ethylbenzene and o-xylene gas phase photodegradation by titanium dioxide dispersed in cementitious materials using a mixed flow reactor, Appl. Catal. B: Environ. 61 (2005) 90-97. doi:10.1016/j.apcatb.2005.04.009.

[29] F. Mothes, O. Böge, $\mathrm{H}$. Herrmann, A chamber study on the reactions of $\mathrm{O}_{3}, \mathrm{NO}, \mathrm{NO}_{2}$ and selected VOCs with a photocatalytically active cementitious coating material, Environ. Sci. Pollut. Res. 23 (2016) 15250-15261. doi:10.1007/s11356-016-6612-6. 